Article

\title{
Understanding Farmers' Decision-Making in Agricultural Water Fee Payment in China: The Role of Mental Accounting
}

\author{
Weikang Zhang ${ }^{1,2, *}$, Xinhong Fu ${ }^{3}$, Jing Lu ${ }^{1}$, Lin Zhang ${ }^{4}$, Kwamega Michael ${ }^{3}$, Guoqiang Liu ${ }^{3}$, \\ Fan Yang ${ }^{3}$ and Yuying Liu ${ }^{3}$ \\ 1 School of Economics and Business Administration, Chongqing University, No. 174 Shazheng Street, \\ Shapingba District, Chongqing 400044, China; lujing@cqu.edu.cn \\ 2 Postdoctoral Research Station, Chongqing Rural Commercial Bank, No. 10 Yanghedong Road, \\ Jiangbei District, Chongqing 400020, China \\ 3 School of Management, Sichuan Agricultural University, No. 211 Huiming Road, Wenjiang District, \\ Chengdu 611130, China; f475994803@163.com (X.F.); KwamegaMichael@163.com (K.M.); \\ 18380443781@163.com (G.L.); YFQSYS1987@163.com (F.Y.); yuyingliu820@163.com (Y.L.) \\ 4 School of Economics and Management, Southwest University, No. 2 Tiansheng Road, BeiBei District, \\ Chongqing 400715, China; zhanglin2762@126.com \\ * Correspondence: zhangweikang99@163.com; Tel.: +86-23-67637933
}

Academic Editor: Ashok K. Chapagain

Received: 27 March 2016; Accepted: 25 August 2016; Published: 31 August 2016

\begin{abstract}
To better understand farmers' refusal to pay agricultural water fees under the current policy in rural China and their corresponding negative emotions, this paper applies mental accounting, a behavioral economics framework, to explore how the governmental policies of reform of rural taxes and fees, direct agricultural subsidy programs, and agricultural water fees individually influence farmers' decisions in paying the agricultural water fees. Using fieldwork data from 577 farmers and 20 water managers in Sichuan, we explore farmers' information processing regarding paying agricultural water fees via three sequential mental accounting processes, with the associated underlying principles and measures behind each process. We find that the information processing in three mental accounting scenarios related to the agricultural water fee elucidates farmers' observed behaviors in rural China. Generally, in the three mental accounting scenarios, two conditional intuitive expectations and nine conditional intuitive preferences are formed; however, the conditions of those expectations or preferences cannot be matched with the facts due to the reform of rural taxes and fees, the direct agricultural subsidy programs, and the internal attributes of agricultural water fee, which interpret those negative behaviors in rural China. Additionally, this paper offers a view into how previous policies create negative psychological externalities (such as farmers' psychological dependence on the government) through mental accounting to negatively influence agents' subsequent decision-making; it highlights the significance of underlying mental factors and information processing of negative behaviors in policymaking for managing or conserving common pool resources.
\end{abstract}

Keywords: mental accounting; agricultural water fee; behavioral economics; decision-making; information processing; representativeness; negative psychological externalities

\section{Introduction}

Most countries are considering pricing and charging for agricultural water resources as an economic instrument for managing and saving water. However, a notable issue facing many 
developing countries is the poor execution of such agricultural water fees (AWF), particularly in China [1].

In rural China, AWF have long been charged by local governments, for instance, in the world-renowned Dujiangyan Irrigation District for over 2000 years [2]. However, in 2006, a majority of farmers suddenly refused to pay or showed negative emotions (conflicts, complaints, and angry expressions) related to paying AWF [3], which resulted in a dramatic decrease in collection rates. After 2006, collections were reduced by $23 \%, 25 \%$, and $40 \%$ in Zhejiang, Jilin, and Guangdong, respectively [3]. A survey disclosed that the average collection rate for 551 irrigation districts in 26 provinces was $57.37 \%$ in 2005 [4], but it dropped to $34 \%$ for 100 typical irrigation districts in 2007 [1]. Notably, expressions of negative emotions and refusal to pay AWF are still observed [5].

Rural China has recently been experiencing major changes through some special supporting policies. For example, China initiated a reform of rural taxes and fees (RTF) in 2001, mainly aimed at cancelling items charged by the government (that is, subject to "political charges"). Rural taxes mainly refer to agriculture-related taxes (such as taxes for agriculture, animal husbandry, cultivated land use, and special agricultural products). Rural fees mainly refer to five "unified planned" fees (such as fees for social assistance, family planning, education supplement, collective transportation, and militia exercise) and three "retained" fees (public accumulation fund, public welfare fund, and administrative). RTF have a long history and its rural taxes date back to the Shang Dynasty (1600 B.C. to 1066 B.C.) [6]. However, in 2006, the government abolished nearly all of these taxes and fees through RTF reform [7]. Meanwhile, the Chinese government has developed various direct agricultural subsidies (DAS) programs since 2003, such as the so-called "Four Direct Subsidy Programs" for grain producers, for integrated agricultural materials, for agricultural machinery purchases, and for superior grain cultivators. These subsidies have provided increasing support for agricultural production over this period [8].

Nevertheless, AWF institutions have not recently changed. Most importantly, AWF is a typical political charge but was emphatically excluded in the RTF reform and DAS programs, making it the solitary political charge in rural China today. It appears that the above observed negative behaviors concerning paying AWF can be partially attributed to the governmental policies of RTF reform and DAS programs.

China is engaging in large-scale reforms related to agricultural water use, which is clearly a concern for further institutional reforms. Thus, elucidating how the RTF reform and DAS programs influence farmers' AWF payment decision-making is significant for developing successful policies.

We seek to address this issue from a psychological decision-making perspective using mental accounting (MA), a theoretical framework from behavioral economics, to answer the following four questions in rural China:

- Question 1: Why did farmers suddenly refuse to pay AWF in 2006?

- Question 2: Why did farmers suddenly show negative emotions (such as anger, complaints, and dissatisfaction) toward paying AWF in 2006?

- Question 3: Why do farmers continue to exhibit such refusal behaviors?

- Question 4: Why do farmers continue to display such negative emotions?

This paper proceeds as follows. Section 2 provides a literature review related to the above questions. Section 3 presents the theoretical framework of MA used to interpret observed behaviors, including the illustration of its applicability to this subject, its rationales, three sequential decision-making processes, and the underlying principles and measures behind each process. Section 4 describes the fieldwork and data collected in the sampling area, Sichuan. Section 5 employs MA to analyze farmers' decision-making in paying AWF. It demonstrates the salience of the abovementioned questions in the sampling area. It also highlights farmers' information processing when paying AWF via MA to elucidate the questions. Section 6 concludes. Section 7 presents implications and limitations. 


\section{Literature Review}

Previous research has identified three ways to interpret the negative behaviors described above. First, they can be attributed to the economic affordability of AWF because farmers' well-being is influenced by paying AWF [9]. However, this connection is not reasonable since Chinese farmers' net income per capita in 2005 increased 3.04 times to 9892 yuan in 2014, and both RTF reform and DAS programs alleviated farmers' tax burden; for instance, through RTF reform, farmers' expenses were reduced by more than 125 billion yuan, with an average reduction of over 140 yuan per farmer [10], and the total funds distributed by the Four Direct Subsidy Programs increased 10.49 times from 2004 (14.52 billion yuan) to 2012 (166.8 billion yuan) [8]. Furthermore, AWF has been set at a low and stable level; for example, the average fees in 2000, 2005 and 2013 were 0.028 yuan $/ \mathrm{m}^{3}$ [11], $0.065 \mathrm{yuan} / \mathrm{m}^{3}$ (accounting for $38 \%$ of the supply cost) [4], and 0.091 yuan $/ \mathrm{m}^{3}$ (accounting for $35.59 \%$ of the supply cost), respectively [12]. The fee in 100 typical water sectors increased by approximately $10 \%$ from 2003 to 2011 [13], while other areas, such as Sichuan, have not seen increases since 2003 [2].

Second, some studies suggest that those behaviors can be attributed to having a willingness to pay a lower amount than the set fee [14]. Even if willingness to pay can be defined as a mental dependent variable connected to the above behaviors, existing research has concentrated on the importance of willingness to pay rather than on the mental processes connecting it to behaviors.

Third, these behaviors can be attributed to three remaining factors. On the one hand are the limitations in the management of AWF, such as opaque water prices and limited information about water volumes used, poor user participation management, lack of supervision for collection and use of the $\mathrm{AWF}$, and ineffective propaganda $[1,3,9]$. On the other, there is a sense of inequity concerning AWF charges, as AWF has become the only channel through which local water managers can raise prices, add surcharges, and intervene as they did before RTF reform [1,3]. These practices have deteriorated farmers' perceptions about the fairness of AWF charges, which causes misunderstanding and dissatisfaction [3]. Finally, concerns regarding the conservation of water infrastructures, such as the lack of volumetric metering facilities, maturation of some long-established irrigation facilities, ineffective dredging of canals, and the damage to and disrepair of caudal canals $[1,3]$ may motivate farmers' negative emotions. The result of this work may enable us to take some actions from the perspective of policymakers. However, implications from the perspective of policy recipients or participants (such as farmers) must also be considered. Thus, we need to understand how farmers make decisions about paying AWF.

In summary, previous research has not addressed the questions that we consider in this paper. Examining the above questions through the MA framework can enhance our understanding of how other agricultural policies psychologically affect farmers' decisions to pay AWF. This knowledge can help improve farmers' compliance and the effectiveness of AWF in agricultural water management in the current context in rural China. It can also guide further institutional reforms that can better match farmers' mental models and prevent similar influence in other agricultural policy areas.

Our study contributes to the current literature by using a behavioral economics framework to identify farmers' mental determinants of AWF payment in rural China. More broadly, it contributes to understanding how previous policies created negative psychological externalities, such as farmers' psychological dependence on the government, through MA that influences agents' subsequent decision-making, an effect that needs to be taken into account in policymaking for managing and conserving water resources and other common pool resources.

\section{Theoretical Framework: Mental Accounting (MA)}

\subsection{Applicability of Mental Accounting (MA)}

MA is an appropriate theoretical framework for the aims of this paper. It was defined narrowly by Tversky and Kahneman [15] as a mental outcome frame that is used to jointly evaluate events and the manner in which they are combined. Richard Thaler, who proposed MA, defined it as the cognitive 
activities that individuals and households edit, categorize, budget, and evaluate transactions and other financial events by way of managerial accounting. MA provides agents with inputs to use for an ex post intuitive comparison with other relevant events [16]. Also, MA is an appropriate behavioral analytical framework since paying AWF is an economic or consumption decision for farmers. MA is the main driver of cognitive biases or anomalies based on agents' mental categorizations of economic and consumption decisions $[16,17]$ and, thus, provides rules that can be used to psychologically dissect or understand these anomalies [18]. Considerable experimental or laboratory data have shown that MA influences consumption decision-making [19].

MA exhibits adequate applicability to Chinese farmers. On the one hand, the poor are usually characterized by a high degree of bounded rationality, which is the root of MA. Kahneman [20] maintains that there are two systems processing information in the human brain: System 1 is characterized by fast, automatic, unconscious, intuitive, and experience-based information processing, while System 2 is slow, reflective, deliberative, and analytical. In general, decisions reached via System 1 are highly dependent on agents' knowledge and experience due to bounded rationality. Chinese farmers are particularly short of educational, economic, and vocational training; as a result, they are more likely to intuitively adopt System 1 in decision-making. On the other hand, some research has disclosed a connection between poverty and cognitive capability. For instance, poverty itself can create additional psychological burdens due to the scarcity of financial resources, limiting the cognitive functioning [21], capacity for attention and understanding [22], and self-control [23]. These burdens can further lead the poor to make less rational, short-sighted, or risk-averse decisions [24], and low cognitive capability, in turn, exacerbates poverty. Chinese farmers represent a large group of the poor and are more likely to intuitively adopt System 1 in decision-making.

Empirically, one study using panel data showed that financial decision-making behaviors of Chinese farmers are obviously influenced by MA [25], and experimental evidence from other countries supports this argument as well. For example, cross-sectional studies on remittance behaviors of rural households in Malawi [26] and investment behaviors of the poor in Kenya [27] have demonstrated the adaptability of MA.

Moreover, behavioral economics is useful for identifying the mental decision-making behind behavioral anomalies, such as those addressed in this study. Given the improvement in economic capabilities and in policies supporting agriculture in rural China, farmers' behaviors around paying AWF can largely be regarded as a particular type of anomaly. Typically, behavioral economics incorporates cognitive psychology to investigate phenomena that cannot be satisfactorily explained by traditional economics. Conventional economics concerns behavioral results, while psychology pays more attention to the premise of behavior under hypothesis of bounded rationality. Behavioral economics should not be considered a subfield of economics but a tool for all economists. Behavioral economics can contribute to public policy in three ways: (a) providing new policymaking instruments; (b) improving the effectiveness of previous polices; and (c) generating novel welfare implications [28].

Interdisciplinary research integrating behavioral economics into environmental and resource economics has been recently appreciated and recommended internationally [29] in areas such as climate change [30] and energy consumption [31] that greatly concern both academics and governments. This tendency reflects a research agenda incorporating psychology to describe or predict anomalous behaviors, especially concerning environmental goods and public resources.

Using behavioral economics to examine water users' behaviors is well recognized as a step worth pursuing. For instance, Russell and Fielding [32] stated that psychological and behavioral factors are critical to understanding water demand behaviors. Survey data from southeast Queensland demonstrated that psychological variables are key determinants of water use behaviors [33]. Jorgensen et al. [34] noted that psychological and behavioral science could help determine users' actual behavioral incentives for water consumption and protection. Correia and Roseta [35] reviewed the research addressing water demand and pricing over the past decade and found that behavioral economics and psychological theories are rarely incorporated into water resource research; thus, they encouraged researchers to devote more attention to this gap. 


\subsection{Rationales}

The rationales underlying MA can be described as System 1, heuristics and categorization heuristics. The two-brain system mentioned above is the starting point at which human decision-making is activated, and MA is a mental judgment made under uncertainty using System 1 [20]; therefore, the system is a prime driver of MA. Second, information processing through System 1 leads to heuristics, of which MA is an example [20]; therefore, the system can represent another rationale for MA. Third, agents often process information through categorization heuristics [36]. In the field of economic decision-making, MA is a classic categorization heuristic [18]. The influence of MA on behaviors can be attributed to distinct ways of information processing in different categories caused by categorizing.

\subsection{Three Sequential Decision-Making Processes and Underlying Principles behind Each Process}

A decision-making process is the frame and trajectory of information processing used to comprehend agents' behaviors. The sequential decision-making processes of MA and principles underlying each process must be illustrated when using it to analyze behaviors in a theoretical framework.

Kahneman and Tversky [37] held that heuristic consists of two activities: editing and evaluating. Thaler [16] proposed that MA includes four cognitive activities: editing, categorizing, budgeting, and evaluating. Drawing on those arguments and the goal of each activity, we propose a framework of three sequential processes for MA decision-making described in Chart 1 . The three processes and underlying principles are explained next.

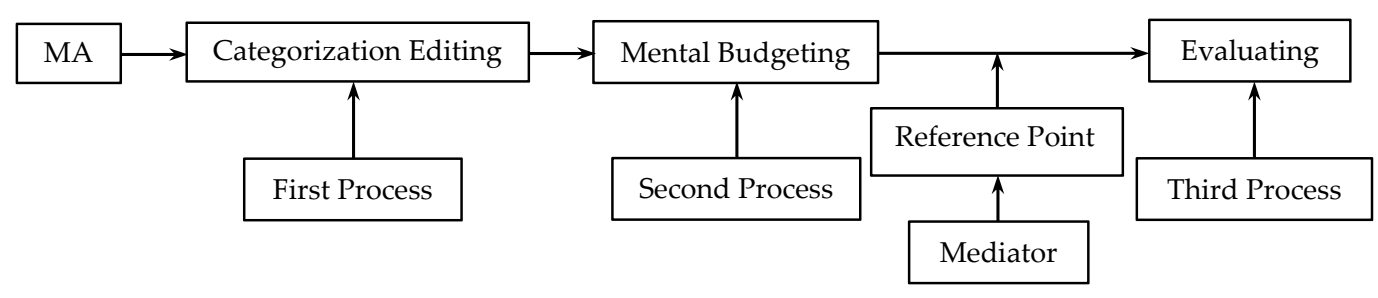

Chart 1. Three sequential decision-making processes of MA.

\subsubsection{Categorization Editing and Underlying Principles}

Incorporating the above two-phase [37] and four-phase [16] processes, the goal of editing is to mentally stratify events. Thus, we integrate editing and categorizing into a single process: categorization editing.

As for the underlying principles, canonical heuristic principles can provide a basis for categorization editing. Tversky and Kahneman [38] proposed three decision-making principles in heuristics: representativeness, availability, and anchoring, where each plays a role in categorization editing. Importantly, representativeness is the primary principle, as it may mediate availability and anchoring.

Principle of Representativeness: Representativeness means that the more similar (or consistent) the representativeness of various events is, the more likely the agent is to assign them into the same mental category, such as the same MA; the more dissimilar they are, the more likely they are to be placed in different mental categories.

Principle of Availability: Availability means that if an event with specific representativeness is more easily perceived or recalled, the possibility is higher that other events sharing this or a similar representativeness will be judged rapidly and with a higher weight. Availability indicates that if event $\mathrm{B}$ is the target event, and it shares representativeness with event $\mathrm{A}$, the greater the availability of this representativeness, the more likely both events are to be assigned to the same MA.

Principle of Anchoring: Anchoring means that the prior information or experiences anchored in the mind will influence subsequent decisions. Anchoring indicates that if event $B$ is the target event, and it shares representativeness with a previous event $\mathrm{A}$, the more deeply this representativeness is anchored, the more likely both events are to be assigned to the same MA. 


\subsubsection{Mental Budgeting and Underlying Principles}

Mental budgeting refers to a process through which agents integrate stimulating factors to track and predict target events. This process uses various principles through mental resource allocation to eventually shape a reference point, such as an expectation or a preference, according to agents' wishes. Kahneman and Tversky [37] noted that a subliminal reference point is formed via a series of information processing activities before evaluating.

Principle of Nonfungibility: Nonfungibility is the most typical budgeting rule in MA [16]. It can cause discrimination against diverse MAs in decision-making, resulting in inappropriate mental resource allocations for those MAs; as a result, some will be valued while others will not.

Principle of Hedonic Editing: Hedonic Editing affects whether agents prefer the integration or the separation of various events in mental budgeting. Thaler [16] indicated that when agents confront two or more net loss events, they might prefer integration to separation of those events, which is one rule of Hedonic Editing (for more rules, see Thaler [16]).

Principle of Dual-Entry MA: The order of payment and consumption and the interval between the two matter in mental budgeting. Agents intuitively prefer to pay first and then consume, with a long interval between both acts to better enjoy the pleasure of consuming. Prelec and Loewenstein [39] considered consumption activities to be primarily composed of the acts of paying and consuming, and agents can use a prospective dual-entry MA to create a distinctive hedonic valuation. For example, the act of paying creates the pain of paying, while the act of consuming creates the pleasure of consuming. The coupling effect of dual hedonic valuation is critical and depends on the order of the acts, as well as the interval between them. The ideal scenario is for the pain of paying to be completely coupled with the pleasure of consuming, while the pleasure of consuming would be as decoupled as possible from the pain of paying.

Principle of Reference for Expectation Dependency: If both events are in the same MA, previous experience of event $B$ will act as a reference for expectations of event $A$; therefore, judging event $A$ will depend on how event $B$ was judged. As a result, the judgments of both events may be similar or even identical. We call this the principle of Reference for Expectation Dependency. Even if agents are uncertain about how to judge event $\mathrm{A}$, it is easy and quick for them to search for similar or correlated events (such as event B) through a heuristic involving attribute replacement [40].

Principle of Depreciation of Opening: The frequency with which one MA is opened influences mental budgeting. A lower frequency of opening a particular MA means that the marginal willingness to budget or the mental resources allocated to events in this MA will be low. Normally, if an MA is opened with a higher frequency, agents are more likely to continue opening it over time due to the inertia created by the mental familiarity of repeated openings, and agents may intuitively assign a greater weight to higher-frequency events and a lower weight to lower-frequency events. Conversely, if an MA is not opened frequently, agents' inertia will lead them to open it quite rarely, which will negatively influence its opening over time. We call this mental effect the Depreciation of Opening Principle.

Principle of Endowment Effect: Endowment Effect indicates that different property rights will result in different evaluations due to asymmetric mental assessments of gains and losses. For example, if an agent's pricing for a product is A when he owns it but B when he does not, then A is usually higher than B. Thus, the degree of ownership and its change matter in mental budgeting.

Principle of Loss Aversion: If agents believe that an event may cause a net loss, this event might be intuitively avoided or discriminated against when allocating mental resources due to mental aversion; this principle is fundamental to understanding decision-making results.

\subsubsection{Evaluating and Underlying Principles}

At this stage, agents combine the reference point (as the mediator) formed through the two earlier processes with the facts to evaluate and make a final decision.

Principle of Matching: If the facts match or exceed expectations, the event will be evaluated positively; on the contrary, if the facts fall short of expectations, the event will be evaluated negatively. Matching is the most fundamental and general principle in evaluating. 
Principle of Norm Theory: Norm Theory indicates that the more incompatible the match, the stronger the resulting emotional reaction. Emotional reactions are usually positive or negative. If the expectation is matched or exceeded by the facts, emotional response will be positive, as in surprise or delight. On the contrary, if the facts fall short of expectations, emotional response will be negative, as in conflicts, complaints or anger. Norm Theory is appropriate for analyzing anomalies, particularly when stressing agents' emotional responses via matching [41].

\subsection{Measures in Three Decision-Making Processes}

\subsubsection{Measures in Categorization Editing: Salient Representativeness}

Salient representativeness is the most significant type of representativeness influencing MA decision-making. Therefore, we focus on the respective salient representativeness of AWF, RTF and DAS and compare them to seek out their consistent salient representativeness.

Salient representativeness can usually be elicited by a high probability of a perception or preference in agents' cognition. We draw on a typical method, descriptive analysis, to investigate the probability of perception and, thereby, to identify the salient representativeness; this method was used by Thaler [16] as well as Kahneman and Tversky [37] to elicit the probabilities of respondents' perceptions or preferences in discussing mental effects.

\subsubsection{Measures in Mental Budgeting and Evaluating: Attributes}

Attributes are key factors that stimulate mental acts of budgeting and evaluating in agents. Attributes of an event can be internal (termed "internal attributes" in this paper) or correlated with other events (termed "correlated attributes" in this paper), e.g., events in the same MA. Usually, internal attributes are characteristics or representatives of an event, and correlated attributes are important acts occurring within correlated events or belonging to policies enjoyed by correlated events. In this study, correlated attributes refer to those between AWF and RTF as well as between AWF and DAS; internal attributes refer to those in AWF in rural China.

\section{Fieldwork and Data}

\subsection{Study Sites}

Our fieldwork was conducted in 33 state-owned irrigation districts located in 20 counties in Sichuan Province, China, which are described in Figure 1 and Table 1.

Table 1. Counties and irrigation districts selected for sampling in Sichuan.

\begin{tabular}{cccc}
\hline Counties & Irrigation Districts & Counties & Irrigation Districts \\
\hline Pengshan (PS) & Tongjiyan & Nanbu (NB) & Baertan, Shengzhong \\
Danling (DL) & Shengli & Hongya (HY) & Hanwang \\
Shifang (SF) & Renminqu & Renshou (RS) & Heilongtan \\
Pujiang (PJ) & Yuxihe & Minshan (MS) & Yuxihe \\
Dayi (DY) & Dujiangyan & Wusheng (WS) & Wupanshui \\
Langzhong (LZ) & Shitan, Guanliang, Shengzhong & Mianzhu (MZ) & Guansongpeng, Hongyanqu, Renminqu \\
Miyi (MY) & Huangqiao, Hongqiqu & Longchang (LC) & Guyumiao, Shipantan, Yanjiatan \\
Yanbian (YB1) & Gaoyangou, Huimindayan & Shehong (SH) & Renminqu, Dujiangyan, Wuyin \\
Luxian (LX) & Zhumeitan, Maojiayan & Weiyuan (WY) & Changhu, Hulukou, Qingfeng, Hekou \\
Yibin (YB2) & Shaoehu, Baijiaba & Fushun (FS) & Pipagou, Bodaoling, Qianzigeng \\
\hline
\end{tabular}

We selected Sichuan as the study site for two reasons. First, farmers in Sichuan provide an adequate sample for investigating the aforementioned questions in China. As of 2012, there were 45.07 million rural residents in Sichuan, accounting for $56.47 \%$ of all residents. Sichuan is also the most important grain-producing province in western China; the major local crop is grown in paddies, which are characterized by rigid and intense water demand. Therefore, Sichuan has high water demand, 
particularly for irrigation, reaching approximately 15 billion cubic meters irrigated over an area of approximately 37 million acres annually. Although AWF is commonly charged in Sichuan, the patterns noted above are clearly observed in this region, and they represent the most prominent, typical and difficult issues facing local governments and managers in rural areas [3].

Second, farmers in Sichuan provide a good transitional explanatory element for linking higherand lower-income farmers throughout the country. We aim to study the psychological factors of economic decision-making among residents who are engaged in traditional farming activities and represent a low-income group in China. The per capita income of farmers in Sichuan ranked 21st among 31 provinces from 2007 to 2013 in China, demonstrating that the economic conditions of farmers in Sichuan were relatively stable and remained near the middle of the range for the entire country over past several years.

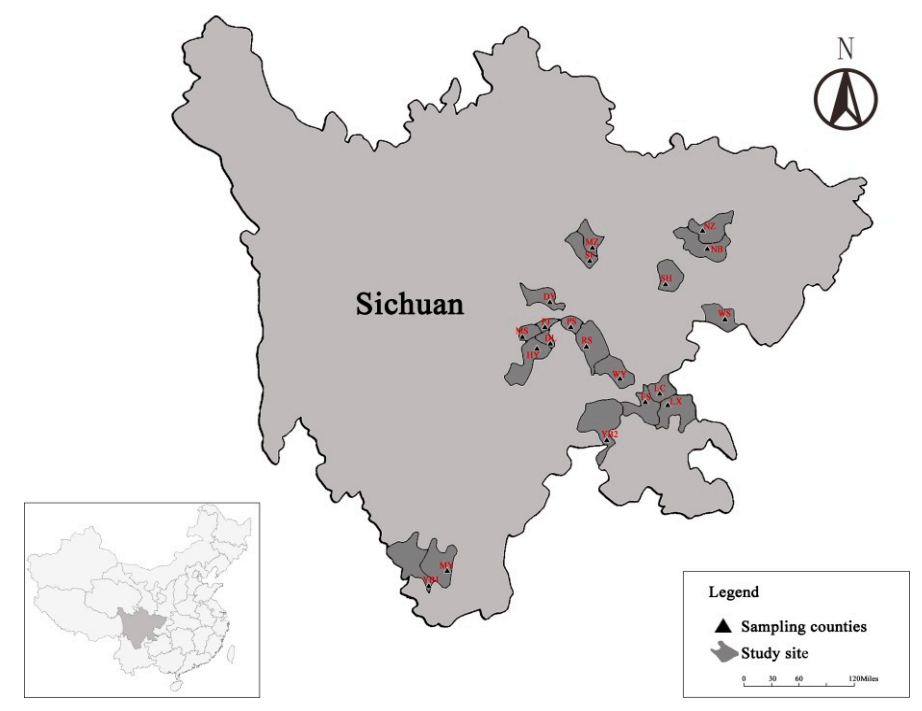

Figure 1. Location of the counties selected for sampling in Sichuan. Note: The sampling counties and their abbreviations are displayed in Table 1.

\subsection{Sampling}

\subsubsection{Questionnaire Design}

The main respondents in our study were farmers who were cultivating paddies, paying AWF and living in the irrigation districts displayed in Table 1 . The other respondents were water managers in the selected counties.

Two questionnaires were designed. The questionnaire for farmers consisted of three parts: (a) part one included questions on farmers' demographics and economic conditions; (b) part two included questions on farmers' cognition of AWF, including information about irrigation districts, charging sectors, acres irrigated, total amount and unit price of AWF paid last year, willingness to pay AWF; and (c) part three included questions about farmers' perceptions of the differences between AWF and RTF, as well as between AWF and DAS.

The questionnaire for managers covered four aspects through open-ended questions: (a) circumstances of local AWF, such as the frequency, collection methods and charging patterns; (b) information on local irrigation districts and recommended townships for sampling; and (c) local farmers' behaviors or attitudes toward paying AWF due to RTF reform and DAS programs, as well as their interpretations of these behaviors. 


\subsubsection{Sampling Procedures}

The fieldwork was conducted during July and September 2013 in four steps. First, before final investigation, we conducted preparatory work to improve questionnaires and communication, including brainstorming sessions, focus groups, conducting a pilot study and training enumerators. Second, 20 counties were chosen based on their size (large, medium, and small) and distribution of irrigation districts in Sichuan. The major irrigation districts in Sichuan within these three size categories were all considered. Third, enumerators scheduled and conducted interviews with local water district managers and asked them to recommend two or three townships in each county based on the rule that townships with better and worse implementation of local AWF should be included. Fourth, the enumerators visited the townships and village leaders, who helped them randomly select 25 to 30 farmers who paid AWF for face-to-face interviews. To incentivize farmers to participate in our fieldwork, we prepared a gift for each of them.

\subsection{General Demographic Characteristics}

This fieldwork involved 595 farmers and 20 managers; 587 farmer questionnaires and 20 manager questionnaires were successfully gathered, and data for 577 farmers and 20 managers are used in this paper.

General demographic characteristics show that the sampled farmers were older, less educated and lower income, which is a realistic portrayal of farmers left behind in contemporary rural China. The following characteristics are considered: age (Mean $=47.94$; Standard Deviation $(\mathrm{SD})=10.70$ ); sex (female $(39.66 \%)$, male $(60.34 \%)$ ); years of education (Mean $=6.94 ; \mathrm{SD}=3.22)$; number of family members (Mean $=4.91 ; \mathrm{SD}=1.75$ ); and personal annual income (Mean $=1.31 ; \mathrm{SD}=0.75$; this factor was measured using categories with a grading standard of 5000 yuan, e.g., $1=$ fewer than 5000 yuan, $2=5000-10000$ yuan).

\section{Using Mental Accounting (MA) to Understand Farmers' Decisions to Pay Agricultural Water Fee (AWF)}

Before employing the MA framework and data to explore the four aforementioned questions, testing the salience of those questions and respondents' cognitive causes from the perspectives of both farmers and managers in the sampling area, Sichuan, is necessary.

\subsection{Testing the Questions and Cognitive Causes of Respondents}

\subsubsection{Are Negative Behaviors Observed at the Study Sites?}

Testing the sampled farmers: Suppose that when farmers' willingness to pay AWF equals 0 or is lower than the required AWF, they might refuse to pay or display negative emotions in paying AWF. Using data from part two of the farmer questionnaire, Table 2 compares the willingness to pay and required AWF, indicating that up to $92.72 \%$ of sampled farmers might refuse or show negative emotions. Additionally, when some sampled farmers learned that enumerators were graduate and undergraduate students researching AWF rather than civil servants, they expressed dissatisfaction with or complaints about paying AWF to them.

Table 2. Comparison of farmers' willingness to pay and the required AWF.

\begin{tabular}{clcc}
\hline & & Frequency & Proportion \\
\hline \multirow{3}{*}{ Willingness to pay $\neq \mathbf{0}$} & Willingness to pay > Required AWF & 11 & $1.91 \%$ \\
& Willingness to pay = Required AWF & 31 & $5.37 \%$ \\
& Willingness to pay < Required AWF & 296 & $\mathbf{5 1 . 3 0} \% \mathbf{9 2 . 7 2} \%$ \\
Willingness to pay = 0 & 239 & $\mathbf{4 1 . 4 2 \%} \mathbf{9}$ \\
$\quad$ Total & 577 & $\mathbf{1 0 0 \%}$ \\
\hline
\end{tabular}


Testing the interviewed managers: Data from manager questionnaires indicate that nearly all managers noted that when RTF were cancelled in 2006, sudden refusals and negative emotions about paying AWF were clearly observed among farmers. They also stressed that even after RTF's cancellation and DAS's implementation, conflicts and complaints about paying AWF persist and are still observed apparently.

Therefore, our data demonstrate that the above four research questions can be identified in the study sites in Sichuan.

\subsubsection{Respondents' Cognitive Causes}

Testing the sampled farmers: In part two of the farmer questionnaire, farmers were given the following prompt: "If you believe that the government should no longer charge an AWF, please select your reasons." Table 3 shows the statistics for their choices, which indicate that government-related factors (R1, R2 and R3) account for up to $93.51 \%$.

Table 3. Reasons farmers thought they should not pay the AWF.

\begin{tabular}{lcc}
\hline \multicolumn{1}{c}{ Reasons } & Frequency & Proportion \\
\hline R1: AWF should be undertaken by the government. & 296 & $\mathbf{3 2 . 5 6 \%}$ \\
R2: Long-term RTF have been exempted, so should AWF. & 246 & $\mathbf{2 7 . 0 6 \%}$ \\
R3: AWF should be subsidized by the government due to the intensified & 308 & $\mathbf{3 3 . 8 8 \%}$ \\
DAS programs. & 40 & $4.40 \%$ \\
R4: We built water conservancy projects, so we should not pay the AWF. & 19 & $2.09 \%$ \\
R5: AWF is not affordable due to my low income. & \\
\hline
\end{tabular}

Note: Farmers could make multiple selections.

Testing the interviewed managers: Using data from 20 manager questionnaires, at least 15 managers indicated that farmers' behaviors in paying AWF can be attributed to their gradually strengthening psychological dependence on the government. As long as the government provides and increases assistance or giving, they continue to hope that the government could provide or give more.

Therefore, our data indicate that the government-related factors or policies are important in influencing farmers' behaviors in Sichuan.

Next, MA framework and obtained data will be used to probe how the aforementioned government-related factors or policies, RTF reform, DAS programs, and AWF influence farmers' behaviors around paying AWF.

\subsection{Salient Representativeness in Categorization Editing}

Data from part three of the farmer questionnaire will be used to elicit the salient representativeness of AWF, RTF and DAS, respectively.

\subsubsection{Salient Representativeness of AWF}

Agricultural production cost: Statistics suggests that agricultural production cost is a salient representativeness of AWF in farmers' perceptions. AWF is one of four types of agricultural production costs in rural China, along with investments in seeds, pesticides, and fertilizers; however, we need data to verify that farmers recognize this subjectively, so a question (Q1: Do you think AWF is a part of the agricultural production costs?) was designed in the farmer questionnaire. The data, as shown in Table 4, show that 525 farmers answered "yes", accounting for $90.99 \%$ of respondents, while 52 farmers answered "no", accounting for $9.01 \%$.

Political charge: Data also indicate that AWF holds an exceedingly salient representativeness of political charge from farmers' perspective, unlike the other three typical agricultural production costs. Seeds, pesticides, and fertilizers can be acquired via market transactions with haggling and self-determined options in China, whereas agricultural water must be purchased from local 
governmental agencies without such options. In fact, purchasing from the market versus from the government might be a significant element distinguishing political from other types of charges.

Two questions (Q2: Do you think AWF is a type of political charge? and Q3: Do you think that the costs of seeds, pesticides or fertilizers are political charges?) were designed in the farmer questionnaire to verify this observation. As shown in Table 4, for Q2, 550 farmers answered "yes", accounting for a very high $95.32 \%$, while 27 farmers answered "no", accounting for $4.68 \%$. Clearly, AWF is recognized as a political charge by farmers. As for Q3, 508 farmers answered "no", accounting for $88.04 \%$, while 69 farmers answered "yes", accounting for $11.96 \%$.

Table 4. Questions addressing farmers' perceptions of the salient representativeness of AWF, RTF and DAS.

\begin{tabular}{lccc}
\hline \multicolumn{1}{c}{ Questions } & \multicolumn{1}{c}{ Answers } & Total \\
\cline { 2 - 3 } & Nes & No & 577 \\
\hline Q1: Do you think AWF is a part of the agricultural production costs? & $525(90.99 \%)$ & $52(9.01 \%)$ & 577 \\
\hline Q2: Do you think AWF is a type of political charge? & $550(95.32 \%)$ & $27(4.68 \%)$ & 577 \\
\hline $\begin{array}{l}\text { Q3: Do you think that the costs of seeds, pesticides, or fertilizers are } \\
\text { political charges? }\end{array}$ & $508(88.04 \%)$ & $69(11.96 \%)$ & 577 \\
\hline $\begin{array}{l}\text { Q4: Do you think the previous agricultural tax was a part of the } \\
\text { agricultural production cost? }\end{array}$ & $530(91.85 \%)$ & $47(8.15 \%)$ & 577 \\
\hline $\begin{array}{l}\text { Q5: Do you think the previous RTF was a type of political charge? } \\
\text { Q6: Do you think AWF is a type of RTF? }\end{array}$ & $553(95.84 \%)$ & $24(4.16 \%)$ & 574 \\
\hline $\begin{array}{l}\text { Q7: Do you think that DAS programs are implemented by } \\
\text { the government? }\end{array}$ & $542(93.93 \%)$ & $35(6.07 \%)$ & 577 \\
\hline $\begin{array}{l}\text { Q8: Do you think that DAS programs are implemented to } \\
\text { incentivize agricultural production activities? }\end{array}$ & $526(91.16 \%)$ & $51(8.84 \%)$ & 577 \\
\hline
\end{tabular}

\subsubsection{Salient Representativeness of RTF}

Agricultural production cost: The data show that RTF has a salient representativeness of agricultural production cost from farmers' perspective. Rural taxes, the chief component of RTF, primarily refer to agriculture-related taxes, as mentioned earlier. Whether farmers have this perception has been verified by a question $(\mathrm{Q} 4$ : Do you think the previous agricultural tax was a part of the agricultural production cost?). Our data, as shown in Table 4, show that 530 farmers answered "yes", accounting for $91.85 \%$, while 47 farmers answered "no", accounting for $8.15 \%$.

Political charge: Data indicate that RTF also holds an exceedingly salient representativeness of political charge from farmers' perspective. Whether farmers recognize RTF as essentially political charges has been determined by a question (Q5: Do you think the previous RTF was a type of political charge?). Our data, as shown in Table 4, show that 553 farmers answered "yes", accounting for a very high $95.84 \%$, while 24 farmers answered "no", accounting for $4.16 \%$.

\subsubsection{Salient Representativeness of DAS}

Government as the executing sector: The data indicate that the government as the executing sector is a salient representativeness for DAS from farmers' perspective. The government indeed executes DAS programs in China, and whether farmers perceived this has been identified by a question (Q7: Do you think that DAS programs are implemented by the government?). The data, as shown in Table 4, show that 542 farmers answered "yes", accounting for 93.93\%, while 35 farmers answered "no", accounting for $6.07 \%$.

Association with agricultural production: The data also indicate that association with agricultural production is also a salient representativeness for DAS from farmers' perspective. As mentioned 
earlier, DAS programs were initiated to support rural agricultural production in China, and whether farmers perceived this to be the case has been determined by a question (Q8: Do you think that DAS programs are implemented to incentivize agricultural production activities?). The data, as shown in Table 4, show that 526 farmers replied "yes", accounting for $91.16 \%$, while 51 farmers replied "no", accounting for $8.84 \%$.

\subsubsection{Consistent Salient Representativeness}

Consistent Salient Representativeness between AWF and RTF

Consistent salient representativeness: agricultural production cost. There is a high probability that AWF (90.99\% "yes" in Q1) and RTF (91.85\% "yes" in Q4) share a common salient representativeness in some farmers' perceptions of agricultural production cost.

Consistent salient representativeness: political charge. There is another quite high probability that AWF (95.32\% "yes" in Q2) and RTF (95.84\% "yes" in Q5) share a common salient representativeness in some farmers' perceptions of political charge.

Political charge is particularly salient in farmers' perception for the following reasons. First, AWF in rural China are charged by government agencies, such as township governments, village collectives, and water management sectors. Table 5 displays the statistics for agents who levy local AWF in the sampling area based on farmers' responses, and government agencies represent $87.87 \%$. Generally, as long as the charging agents are government-related agencies, farmers may find it difficult to differentiate among the various charges and will consider them all political charges. Second, AWF and other political charges have histories dating back thousands of years in rural China; therefore, all taxes and fees may hold the salient representativeness of political charges anchored profoundly in farmers' perceptions.

Table 5. Statistics for agents charging AWF in the sampling area.

\begin{tabular}{cccccc}
\hline $\begin{array}{c}\text { Charging } \\
\text { Agents }\end{array}$ & $\begin{array}{c}\text { Township Governments } \\
\text { or Village Collectives }\end{array}$ & $\begin{array}{c}\text { Water User } \\
\text { Associations }\end{array}$ & $\begin{array}{c}\text { Water Management } \\
\text { Sectors }\end{array}$ & Others & Total \\
\hline $\begin{array}{c}\text { Frequency } \\
\text { Proportion }\end{array}$ & 452 & 69 & 58 & 1 & 577 \\
\hline
\end{tabular}

Consistent Salient Representativeness between AWF and DAS

Consistent salient representativeness: government as the executing sector. There is a very high possibility that AWF (95.32\% "yes" in Q2) and DAS (93.93\% "yes" in Q7) share a common salient representativeness in farmers' perceptions in that government operates as the executing agent for both of them.

Consistent salient representativeness: association with agricultural production. There is another high possibility that AWF (90.99\% "yes" in Q1) and DAS (91.16\% "yes" in Q8) share a common salient representativeness in farmers' perceptions in that both are related to agricultural production.

\subsection{Attributes in Mental Budgeting and Evaluating}

Data from managers' questionnaires and institutional context of AWF, RTF, and DAS will be integrated to deduce $\mathrm{AWF}^{\prime}$ s correlated attributes and internal attributes.

\subsubsection{Correlated Attributes between AWF and RTF}

Correlated attribute 1: Cancellation of political charges. AWF and RTF are both political charges in farmers' minds, but China has been eliminating political charges since 2001. For example, in RTF reform, the "Three Cancellations Program" removed some fees, taxes and volunteer services, such as the Township Planning Fees, Educational Crowdfunding, Animal Slaughtering Taxes, Rural 
Cumulative Labor Service and Rural Volunteer Service. The "Two Adjustments Program" regulated agricultural taxes, which were then eliminated in 2006. The "One Reform Program" highlighted a revolution in the Rural Accumulation Fund, which was also eventually dismantled in 2006 [7].

Correlated attribute 2: Cancellation of Rural Cumulative Labor Service, Rural Volunteer Service and Rural Accumulation Fund. AWF is the charge for using agricultural water and maintaining water conservation facilities, and three items cancelled by RTF reform were associated with agricultural water resources, they are indirectly relevant to AWF and, thus, to some degree influence farmers' perceptions about paying it. For example, the Rural Cumulative Labor Service stated that farmers should bear annual responsibility for certain tasks related to water conservancy construction and maintenance, such as building and dredging canals. The Rural Volunteer Service stated that farmers should be obliged to manage flood protection, and the Rural Accumulation Fund was designated to be partially allocated to the establishment of irrigation and water conservancy projects [7].

Correlated attribute 3: Identical timing for charges. Before RTF's reform, local government agencies were responsible for collecting a range of taxes and fees in rural China and usually combined most of them for convenience. For example, AWF and agricultural tax were typically collected together [1]. Our interviews with local 20 managers confirmed this practice. Even if they were paid via different means, e.g., paying agricultural taxes with grain but paying AWF in cash, farmers' perception that RTF and AWF share the correlated attribute of identical timing for charges may persist.

\subsubsection{Correlated Attributes between AWF and DAS}

Correlated attribute 4: Agricultural production costs have recently been intensely subsidized. As mentioned earlier, farmers see that AWF and DAS are both related to agricultural production and executed by governments. Moreover, China's central government has been increasingly subsidizing agricultural production costs via DAS programs since 2003 to incentivize agricultural activities. For instance, the "Four Direct Subsidies Program" was recently intensified by increasing a level from 14.52 billion yuan in 2004 to 166.8 billion yuan in 2012 [8].

\subsubsection{Internal Attributes of AWF}

There are four internal attributes of AWF generalized through interviews with 20 water sector managers in the sampling area.

- Internal attribute 1: AWF is generally charged once a year.

- Internal attribute 2: Farmers consume water resources first, but the payment is delayed. Thus, it is a way of consuming first and paying later.

- Internal attribute 3: The interval between consuming and paying is usually one to three seasons.

- Internal attribute 4: AWF is the only remaining political charge in rural China; it is unique locally.

Specifically, our interviews indicated that the major crop in sampling area was single-cropped rice; agricultural water is thus intensively used for annual spring irrigation in April or May; AWF is typically charged once a year after the fall harvest (in August, September, or even later); agencies even collect AWF during the Chinese New Year (usually in January or February of the next year). At least 15 managers argued that due to the increasing difficulty in collecting AWF, it was better to postpone it until the Chinese New Year for several reasons: traditionally, holding onto debt from past year is not propitious for new year in China; the Chinese New Year is the most important annual festival in China, thus, some associated positive emotions can partially offset farmers' negative feelings about paying AWF; and Chinese New Year is also a reunion festival for which many rural migrant workers who are wealthier, more understandable, and thus more likely to pay AWF, return home.

\subsection{Results and Discussion}

Next, using three MA processes successively by incorporating their associated underlying principles and measures, the information processing of decision-making in paying AWF will be 
discussed in three scenarios, because our findings indicate that three AWF-related MAs can be formed in categorization editing.

Notably, the information processing of mental budgeting and evaluating in each MA are combined, because there are various information processing inferences in mental budgeting of each MA, and every inference will result in multiple corresponding results, thereby separating budgeting and evaluating may induce confusion and undermine consistency.

\subsubsection{First Scenario: Information Processing in the Joint MA for RTF and AWF}

\section{Information Processing in Categorization Editing}

In this process, some farmers intuitively combine AWF and RTF them as a group to form the joint MA for RTF and AWF.

RTF is very easily tracked and recalled by farmers when paying AWF. First, in terms of the degree to which the political charge is anchored in farmers' minds, RTF will be the deepest. RTF has a history of several thousand years in China and was the primary and greatest political charge before its reform, making it anchored deeply in farmers' minds. Currently, AWF is the only political charge in rural China, and RTF has become the most probable reference for AWF in farmers' minds. Therefore, according to the principle of Anchoring, RTF will be easily recalled. Second, the relationship between AWF and RTF is very ambiguous in farmers' minds, as they were charged by the same organization (governmental agencies) at the same time. AWF and RTF being closely linked in farmers' minds has been examined by a question (Q6: Do you think the AWF is a type of RTF?) in the farmer questionnaire. Our data, as shown in Table 4, show that 544 farmers answered "yes", accounting for as high as $94.28 \%$. According to the principle of Availability, if AWF is highly related to RTF, the probability and speed of RTF being tracked and recalled in memory are high.

When RTF is tracked and recalled in paying AWF, both of them will be mentally combined to create a joint MA in farmers' minds. Because they share two points of salient representativeness (agricultural production cost and political charge) from farmers' perspectives, according to the principle of Representativeness, in this manner, they readily combine to form a joint MA.

\section{Information Processing in Mental Budgeting and Evaluating}

Farmers form one conditional intuitive expectation and four conditional intuitive preferences in mental budgeting; however, these conditions are not matched during evaluating, which partly illuminates the above four questions in China.

The conditional intuitive expectation in mental budgeting: AWF could be cancelled as with the cancellation of RTF. Because AWF and RTF are in the same MA, when most political charges were removed by RTF reform in 2006 (correlated attribute 1), according to the principle of Reference for Expectation Dependency, the experience of RTF (cancelled) served as a reference for farmers' expectations to AWF. Therefore, they have been wishing that AWF could also be cancelled since 2006, and this sense of expectation was the strongest when other political charges were completely eliminated via RTF reform in 2006.

However, in evaluating, this expectation has not been satisfied, because its condition cannot be matched with the fact that AWF has not been cancelled. According to the principle of Matching, farmers have been negatively evaluating paying AWF since 2006, which partially explains why refusal behaviors have been seen until now (Question 3). Additionally, this expectation of cancellation was strongest in 2006, but it was not met at that time; farmers suddenly began to refuse to pay AWF (Question 1). Further, according to the principle of Norm Theory, this context can partially explain why negative emotions (such as conflicts, complaints, and angry expressions) were suddenly observed (Question 2) in 2006 and can be seen now (Question 4).

The conditional intuitive preference in mental budgeting: a higher degree of participation in water-related activities will raise farmers' compliance with paying AWF. According to the principle of Endowment 
Effect, participating in one event denotes enjoying its property rights, thus, raising the participation rate means enjoying greater property rights, causing a stronger perception of ownership and improving compliance.

However, in evaluating, this preference is not satisfied because its condition cannot be matched due to RTF reform. Because these activities were cancelled by RTF reform (correlated attribute 2). Thus, according to the principle of Matching, farmers negatively evaluate paying AWF, which again partially explains why farmers are refusing to pay (Question 3).

The conditional intuitive preference in mental budgeting: if there are other charging items integrated with AWF, farmers will become more likely to pay AWF. According to the principle of Hedonic Editing, when agents face two or more events with a net loss, they prefer integration rather than separation of those events.

However, in evaluating, this preference is not satisfied because its condition cannot be matched due to RTF reform. Before RTF's reform, AWF was usually charged with agricultural tax (correlated attribute 3), which conforms to the preference for integration. Yet, agricultural tax was cancelled by RTF reform, and there are no longer other charges to be integrated with AWF due to its uniqueness in rural areas. Thus, according to the principle of Matching, farmers negatively evaluate paying AWF, which partially explains why farmers are now refusing to pay (Question 3).

The conditional intuitive preference in mental budgeting: if the joint MA for RTF and AWF is considered as a potential net loss, farmers will be averse to opening this MA due to Loss Aversion.

However, in evaluating, this preference is not satisfied because its condition cannot be matched due to RTF reform. In this case, the principle of matching partially explains why farmers are now refusing to pay (Question 3). Currently, AWF represents the entire set of political charges (internal attribute 4), and the net loss is completely psychologically attached to AWF. Accordingly, it is difficult for farmers to mentally open one MA with a potential net loss event, AWF.

The conditional intuitive preference in mental budgeting: if the joint MA for RTF and AWF is opened more frequently, it will become more likely to be opened over time, and farmers' budgeting propensity of mental resources allocated to AWF will be high. According to principle of the Depreciation of Opening, a higher-frequency opening for one MA will create stronger mental inertia toward its opening over time, and vice versa.

However, in evaluating, this preference has not been satisfied because its condition is not matched due to the lower frequency of AWF. This partially explains why farmers' refusal to pay can be seen now (Question 3). Because AWF is now charged once a year (internal attribute 1), the joint MA for RTF and AWF is opened once a year, which is too low for inertia to lead farmers to open it over time. If this joint MA is not opened, it will be discriminated when allocating mental resources, and refusal to pay AWF can be observed.

\subsubsection{Second Scenario: Information Processing in the Joint MA for DAS and AWF}

Information Processing in Categorization Editing

Some farmers intuitively place AWF and DAS programs together in categorization editing to form the joint MA of DAS and AWF.

DAS programs are easily tracked and recalled in farmers' minds when paying AWF. First, DAS programs were initiated in 2003, and its subsidy amount has been increasing, therefore, the degree of anchoring with DAS will also increase gradually. According to the principle of Anchoring, DAS will be easily tracked and recalled in memory. Second, farmers are very sensitive to governmental policies regardless of whether they represent giving or taking. For example, DAS is a type of giving, while AWF is a type of taking; however, as long as they are implemented by the government, they will be mentally linked. According to the principle of Availability, when taking (AWF) occurs, giving (DAS) will be easily tracked and recalled in memory. 
When DAS is tracked and recalled while paying AWF, both of them will be mentally combined to create a joint MA. According to the principle of Representativeness, they share two areas of consistent salient representativeness (the executing sector is the government, and they relate to agricultural production), farmers will combine them mentally to form a joint MA.

\section{Information Processing in Mental Budgeting and Evaluating}

Farmers form one conditional intuitive expectation and one conditional intuitive preference in mental budgeting; however, these conditions are not matched in evaluating. This partly illuminates two of the above questions in China.

The conditional intuitive expectation in mental budgeting: AWF could be subsidized in a way similar to the $D A S$. Because AWF and DAS are in the same MA, and most agricultural production costs have been increasingly subsidized by the government since 2003 (correlated attribute 4), according to the principle of Reference for Expectation Dependency, the experience of DAS (subsidies) has served as a reference for farmers' expectations to AWF. Therefore, farmers have also been intuitively wishing for AWF to also be subsidized since 2003.

However, in evaluating, this expectation has not been satisfied because its condition cannot be matched with the fact that AWF has not been subsidized. According to the principle of Matching, farmers have been negatively evaluating paying $A W F$, thus partially explaining the refusal behaviors seen to date (Question 3). Additionally, Norm Theory can explain why negative emotions (such as conflict, complaints, and anger) are now seen (Question 4).

The conditional intuitive preference in mental budgeting: if the joint MA for DAS and AWF is opened more frequently, it will become more likely to be opened over time, and farmers' budgeting propensity of mental resources allocated to AWF will be high.

According to the principle of Depreciation of Opening, the frequency of annual charge (internal attribute 1) can also block the opening of joint MA for DAS and AWF, which partially explains why refusal behaviors can now be seen (Question 3), as it does in the joint MA for RTF and AWF.

\subsubsection{Third Scenario: Information Processing in the Single MA for AWF}

\section{Information Processing in Categorization Editing}

Given that the uniqueness of AWF highlights its current peculiarity and salience in rural China, some farmers may form a single MA for AWF in categorization editing.

Context is critical for decision-making, namely, information processing for categorization editing is context-dependent, relying on the inclusion and abstraction of representativeness [42]. One event can be grouped either into a MA with other correlated events or into an individual MA. It is more likely to be independently considered when one event is specific or its representativeness is different from that of others. For instance, in terms of the classification of someone's social MA, it can be defined as a relational MA when considering the relationship between him and others, or as an individual MA when considering his individuality or distinctiveness.

Information Processing in Mental Budgeting and Evaluating

Farmers form four conditional intuitive preferences in mental budgeting; however, these conditions are not matched in evaluating, which partly illuminates one of the above questions in China.

The conditional intuitive preference in mental budgeting: if the order is paying first and then consuming, farmers' compliance in paying AWF will raise. According to Dual-Entry MA, if farmers consume first and then pay, the pleasure of consuming is barely coupled with the anticipated pain of paying; they will then have an illusion that this merchandise has nothing to do with them but needs to be paid at full charge. Therefore, due to their pursuit of hedonic pleasure, farmers prefer to pay first and consume later. 
However, in evaluating, this preference cannot be satisfied because its condition is incompatible with the fact that AWF is currently charged in a consume first, pay later manner (internal attribute 2). Based on the principle of matching, this partially explains why refusal behaviors are now being seen (Question 3).

The conditional intuitive preference in mental budgeting: a shorter interval between the acts of paying and consuming can raise farmers' compliance in paying AWF. Because the current order is to consume first and then pay, according to Dual-Entry MA, the shorter the interval between dual acts is, the stronger the coupling of hedonic valuations will be, and the weaker the pain when paying.

However, in evaluating, this preference is not satisfied because its condition cannot be matched by the fact of a relatively longer interval (internal attribute 3). According to the principle of Matching, this gap partially explains why refusal behaviors are currently seen (Question 3 ). This is because the pleasure of consuming over such a long interval is difficult to couple with the pain of paying, causing refusal behaviors when paying AWF.

The conditional intuitive preference in mental budgeting: if AWF is not unusual or is fungible, it will raise farmers' compliance in paying AWF. According to the principle of Nonfungibility, if AWF is not unique, it will not be isolated mentally; thus, farmers will not mentally discriminate against AWF in allocating mental resources.

However, in evaluating, this preference is not satisfied because its condition cannot be matched by the facts: AWF is currently the only political charge in rural China (internal attribute 4). Based on the principle of matching, this will lead farmers to discriminate against this MA when allocating mental resources, causing a low marginal propensity to allocate mental resources to AWF, which partially explains why refusal behaviors can now be seen (Question 3).

In another study involving the same respondents, we verified farmers' lower marginal propensity to allocate mental resources to AWF. Only $4.35 \%$ and $1.91 \%$ of farmers were willing to consider using their farm income and work income (both are conventional and primary sources of revenue for farmers in China), respectively, to pay AWF [43].

The conditional intuitive preference in mental budgeting: if the single MA for AWF is opened more frequently, it will become more likely to be opened over time, and farmers' budgeting propensity of mental resources allocated to AWF will be high.

According to the Depreciation of Opening, the yearly charging frequency for MA (internal attribute 1) can also block the opening of single MA for AWF, which partially explains why refusal behaviors can now be seen (Question 3), as occurs in the joint MA for RTF and AWF, as well as in the joint MA for DAS and AWF.

\subsubsection{Summary of Information Processing for the Decision to Pay the AWF}

Overall, the information processing behind farmers' decisions to pay AWF through MA can psychologically answer the above four questions, as delineated in Chart 2. 


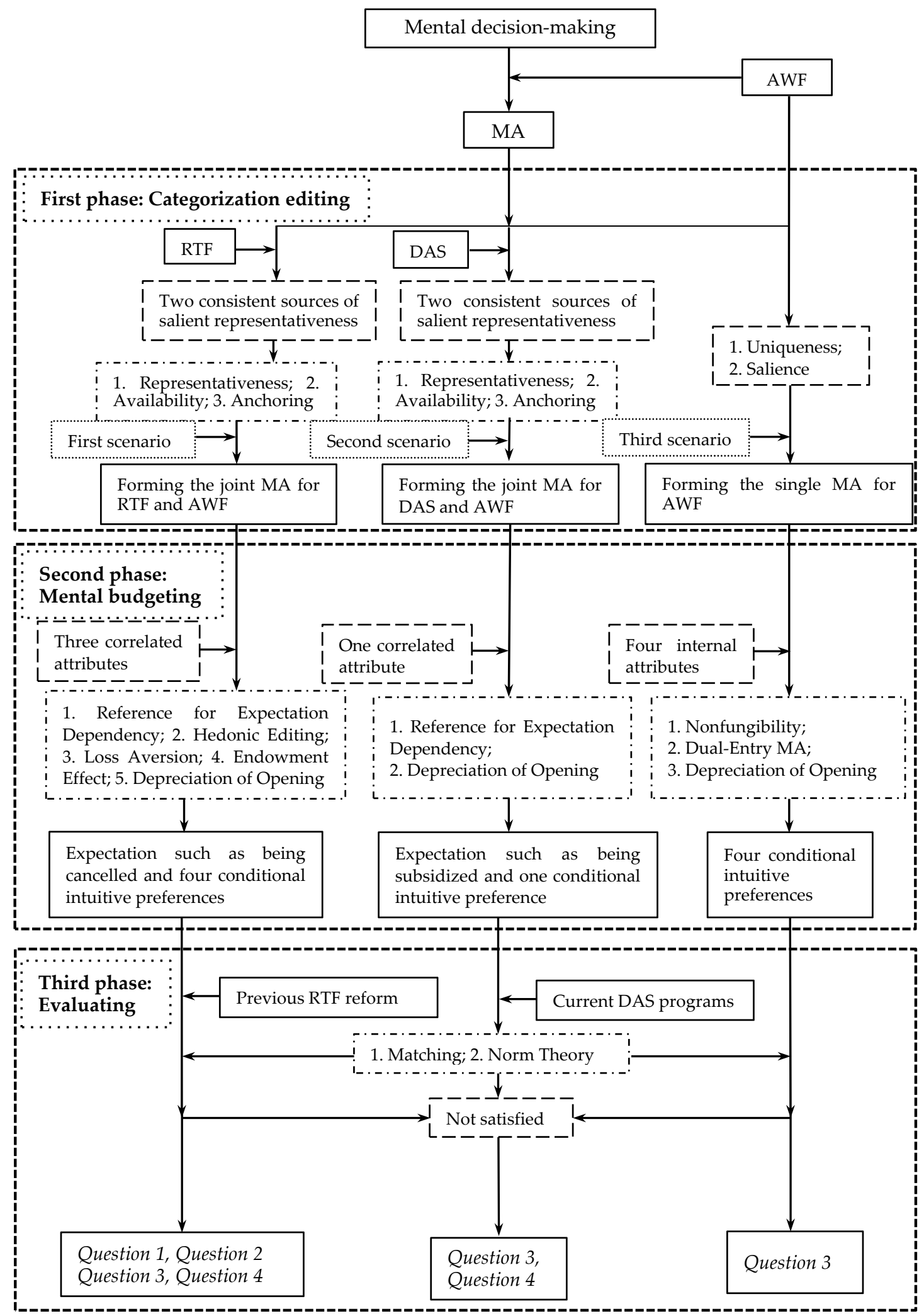

Chart 2. Information processing for farmers' decisions to paying the AWF via MA in China.

\section{Conclusions}

Four questions are raised regarding farmers' negative behaviors when paying AWF in rural China: why did farmers suddenly refuse to pay AWF (Question 1) or show negative emotions (Question 2) in 
2006, and why are such refusal behaviors (Question 3) or negative emotions (Question 4) still seen now? The facts indicate that the governmental policies of RTF reform and DAS programs may have great effects on those behaviors. Our fieldwork data, collected from 577 farmers and 20 water managers in Sichuan, demonstrate the salience of four patterns in the sampling area. Most farmers (93.51\%) reported that they hoped that the government would cover AWF; however, their expectations have not been met, causing their observed negative behaviors. In addition, managers reported that those behaviors can largely be attributed to farmers' increasing psychological dependence on the government.

This paper first applies the behavioral economics of the MA framework to explore how the governmental policies of RTF reform, DAS programs, and AWF individually influence farmers' decisions to pay AWF. Using these fieldwork data, farmers' decision-making regarding paying AWF is explored via the information processing in three sequential MA processes, considering the associated underlying principles and measures behind each process.

Our findings suggest that information processing scenarios in three AWF-related MAs can explain those four research questions raised in China: in the first scenario, according to three principles in categorization editing, some farmers mentally group AWF with RTF to form a joint MA for RTF and AWF based on two points of consistent salient representativeness between RTF and AWF. Then, according to the principle of Reference for Expectation Dependency in mental budgeting, this MA forms one conditional intuitive expectation that AWF can be cancelled like RTF; however, its condition cannot be matched with the fact that AWF has not been cancelled so far, according to the principles of Matching and Norm Theory in evaluating, which explains Question 1, Question 2, Question 3, and Question 4. Meanwhile, according to the other four principles in mental budgeting, this MA also forms four conditional intuitive preferences, but the conditions of those preferences cannot be matched with the facts due to RTF reform and lower annual charging frequency of AWF, according to the principle of Matching in evaluating, which explains Question 3.

In the second scenario, according to three principles in categorization editing, some farmers mentally group DAS and AWF to form a joint MA for DAS and AWF based on two sources of consistent salient representativeness between DAS and AWF. Then, according to the principle of Reference for Expectation Dependency in mental budgeting, this MA forms one conditional intuitive expectation that AWF can be subsidized like the DAS; however, its condition cannot be matched with the fact that AWF is not subsidized currently, according to the principles of Matching and Norm Theory in evaluating, which explains Question 3 and Question 4. Meanwhile, according to the principle of Depreciation of Opening in mental budgeting, this MA also forms another conditional intuitive preference, but its condition cannot be matched with the facts due to a lower annual charging frequency of AWF, according to the principle of Matching in evaluating, which explains Question 3.

In the third scenario, as the categorization editing is context-dependent, some farmers form a single MA for AWF based on its current uniqueness and salience in categorization editing. Then, according to three principles in mental budgeting, this MA forms four conditional intuitive preferences, but the conditions of those preferences cannot be matched with the facts due to four internal attributes of AWF, according to the principle of Matching in evaluating, which explains Question 3.

\section{Implications and Limitations}

Our study provides insights into how negative psychological externalities, such as Chinese farmers' psychological dependence on the government, as reported by interviewed managers, are formed through an MA path. We show that earlier policies can negatively affect agents' compliance with subsequent polices. An increasing level of previous giving, such as eliminating RTF or increasing DAS amount, may increase the likelihood of farmers' psychological dependence on the giver (the government), which results in growing negative mental externalities connected to the fulfillment of future correlated obligations, such as paying AWF. This type of mental effect is more likely to be linked to behaviors in using or conserving common pool resources like the deteriorated water and 
environmental resources. Therefore, when "giving" occurs, noting its resulting negative psychological externalities is critical, and actions are then needed to mitigate the corresponding drawbacks, which can be done via decision-making questing, such as probing the information processing behind behaviors.

Additionally, the information processing framework for decision-making via MA proposed in this study (Chart 2) can be extended to elucidate other daily behaviors, particularly those marked by categorization or negative sentiments.

Lastly, the limitations of this paper point to a need for further work. First, we focused on explaining rather than resolving the abovementioned questions; therefore, follow-up field experiments aimed at improving farmers' compliance with AWF are needed. Thaler and Sunstein [44] argued that when agents' decisions are difficult, infrequent, and have delayed effects, supportive nudging may guide them to reconcile themselves to the decisions and be better off. Thus, considering the decision-making around paying AWF, some choice architecture can be considered to nudge farmers to intuitively change their behaviors. Second, given the small sample size and limited area covered in this study, extensive local fieldwork with more participants is needed as well.

Acknowledgments: The authors are grateful for the insightful suggestions and comments from three anonymous reviewers that greatly improved this manuscript, and acknowledge financial assistance from the National Natural Science Foundation of China (No. 71373296 and 71232004), the National Youth Social Science Foundation of China (No. 14CJY049), and the China Scholarship Council ([2013]3009).

Author Contributions: Weikang Zhang conceived the idea, conducted the fieldwork, and drafted the manuscript. Xinhong Fu contributed to the data collection and analysis. Jing Lu provided suggestions for the structure and contributed to data processing and manuscript editing. Lin Zhang, Kwamega Michael, Guoqiang Liu, Fan Yang and Yuying Liu performed the data analysis, compiled the figures and tables, and offered helpful advice on the drafts. All authors read and approved the final manuscript. Any errors are, of course, ours alone.

Conflicts of Interest: The authors declare no conflict of interest.

\section{Abbreviations}

The following abbreviations are used in this manuscript:

$\begin{array}{ll}\text { MA } & \text { Mental Accounting } \\ \text { AWF } & \text { Agricultural Water Fee } \\ \text { RTF } & \text { Rural Taxes and Fees } \\ \text { DAS } & \text { Direct Agricultural Subsidies }\end{array}$

\section{References}

1. Wang, Y.; Chen, S. Breaking the dilemma of agricultural water fee collection in China. Water Policy 2014, 16, 773-784. [CrossRef]

2. Wang, D.Q.; Lou, Y.H. Thinking on the current agricultural water fee. Water Resour. Dev. Res. 2011, 11, 31-33. (In Chinese)

3. Zheng, T.H.; Zhang, B.; Wang, X.W. The current agricultural water price reform in China: Issues, impacts and countermeasures. China Water Resour. 2006, 57, 17-20. (In Chinese)

4. Zheng, T.H. Promoting the reform of water price and establishing a better operation mechanism for irrigation and water conservancy. China Water Resour. 2007, 58, 29-32. (In Chinese)

5. Zhang, W.K.; Zeng, Y.Y.; Fu, X.H.; Liu, Y.Y.; Zeng, W.Z. Reference point, willingness to pay and irrigation water price: Evidence of 567 farmers from 20 counties in Sichuan. Resour. Sci. 2014, 36, 2020-2028. (In Chinese)

6. Aubert, C.; Li, X.D. Peasant burden: Taxes and levies imposed on Chinese Farmers. In Agricultural Policies in China after WTO Accession; Organization for Economic Cooperation and Development: Paris, France, 2002; pp. 160-179.

7. Huang, Z.G.; Zhang, P.; Zhang, F. The Change of Social and Economic Development in Rural China; China Social Science Press: Beijing, China, 2002. (In Chinese)

8. Tan, Z.X.; Zhou, Z. Relevance between the agricultural subsidies and farmers' enthusiasm for cultivating grain in China. Reform 2014, 27, 94-102. (In Chinese) 
9. Liao, Y.S. Problems and methods for the reform of agricultural water price. China Agric. Water Hydropower 2004, 46, 74-76. (In Chinese)

10. Cheng, G.Q.; Zhu, M.D. Agricultural subsidy institutions and policies in the middle of industrialization in China. Manag. World 2012, 28, 9-20. (In Chinese)

11. Wang, K.Q. Performance Evaluation of the Efficiency and Policy of Irrigation Saving Market in China; Shanghai Renmin Press: Shanghai, China, 2010; pp. 202-241. (In Chinese)

12. Ministry of Water Resources. Statistical Bulletin of the Hydropower Development of China in 2013. Available online: http://www.mwr.gov.cn/zwzc/hygb/slfztjgb/201411/P020141117379140945873.pdf (accessed on 17 December 2015). (In Chinese)

13. Ding, J.; Wan, J.S.; Kang, M. How to promote the reform of agricultural water price in China. Theory Pract. Price 2012, 32, 10-11. (In Chinese)

14. Tang, Z.; Xu, Z.M. Farmers' affordability of irrigation water through the contingent valuation method: Case study of Zhangye. J. Glaciol. Geocryol. 2009, 31, 560-564. (In Chinese)

15. Tversky, A.; Kahneman, D. The framing of decisions and the psychology of choice. Science 1981, 211, $453-458$. [CrossRef] [PubMed]

16. Thaler, R.H. Mental accounting and consumer choice. Mark. Sci. 1985, 4, 199-214. [CrossRef]

17. Thaler, R.H. Mental accounting matters. J. Behav. Decis. Making 1999, 12, 183-206. [CrossRef]

18. Henderson, P.W.; Peterson, R.A. Mental accounting and categorization. Organ. Behav. Hum. Decis. Process. 1992, 51, 92-117. [CrossRef]

19. Hastings, J.; Shapiro, J.M. Mental Accounting and Consumer Choice: Evidence from Commodity Price Shocks. 2012. Available online: http:/ / www.nber.org/papers/w18248 (accessed on 2 June 2015).

20. Kahneman, D. Thinking, Fast and Slow; Macmillan: London, UK, 2011.

21. Mani, A.; Mullainathan, S.; Shafir, E.; Zhao, J. Poverty impedes cognitive function. Science 2013, 341, $976-980$. [CrossRef] [PubMed]

22. Datta, S.; Mullainathan, S. Behavioral design: A new approach to development policy. Rev. Income Wealth 2014, 60, 7-35. [CrossRef]

23. Vohs, K.D. The poor's poor mental power. Science 2013, 341, 969-970. [CrossRef] [PubMed]

24. Haushofer, J.; Fehr, E. On the psychology of poverty. Science 2014, 344, 862-867. [CrossRef] [PubMed]

25. Zhou, J.; Ai, C.R.; Wang, D.F.; Tang, Y. Structural effects of consumption and income in rural China. Econ. Res. J. 2013, 59, 122-133. (In Chinese)

26. Davies, S.; Easaw, J.; Ghoshray, A. Mental accounting and remittances: A study of rural Malawian households. J. Econ. Psychol. 2009, 30, 321-334. [CrossRef]

27. Dupas, P.; Robinson, J. Why don't the poor save more? Evidence from health savings experiments. Am. Econ. Rev. 2013, 103, 1138-1171. [CrossRef]

28. Chetty, R. Behavioral economics and public policy: A pragmatic perspective. Am. Econ. Rev. 2015, 105, 1-33. [CrossRef]

29. Carlsson, F.; Johansson-Stenman, O. Behavioral economics and environmental policy. Annu. Rev. Resour. Econ. 2012, 4, 75-99. [CrossRef]

30. Araña, J.E.; León, C.J. Can defaults save the climate? Evidence from a field experiment on carbon offsetting programs. Environ. Res. Econ. 2013, 54, 613-626. [CrossRef]

31. Allcott, H.; Mullainathan, S. Behavior and energy policy. Science 2010, 327, 1204-1205. [CrossRef] [PubMed]

32. Russell, S.; Fielding, K.S. Water demand management research: A psychological perspective. Water Resour. Res. 2010, 46, 1-12. [CrossRef]

33. Fielding, K.S.; Russell, S.; Spinks, A.; Mankad, A. Determinants of household water conservation: The role of demographic, infrastructure, behavior, and psychosocial variables. Water Resour. Res. 2012, 48, 1-12. [CrossRef]

34. Jorgensen, B.S.; Martin, J.F.; Pearce, M.W.; Willis, E.M. Predicting household water consumption with individual-level variables. Environ. Behav. 2014, 46, 872-897. [CrossRef]

35. Correia, R.; Roseta-Palma, C. Behavioral economics in water management: An overview of behavioural economics applications to residential water demand. In Sustainable Consumption: Multi-Disciplinary Perspectives in Honor of Professor Sir Partha Dasgupta; Ulph, A., Ed.; Oxford University Press: Oxford, UK, 2014; Chapter 9; pp. 196-223. 
36. Fryer, R.; Jackson, M.O. A categorical model of cognition and biased decision making. BE J. Theor. Econ. 2008, 8, 1-44. [CrossRef]

37. Kahneman, D.; Tversky, A. Prospect theory: An analysis of decision under risk. Econometrica 1979, 47, 263-291. [CrossRef]

38. Tversky, A.; Kahneman, D. Judgment under uncertainty: Heuristics and biases. Science 1974, 185, $1124-1131$. [CrossRef] [PubMed]

39. Prelec, D.; Loewenstein, G. The red and the black: Mental accounting of savings and debt. Mark. Sci. 1998, 17, 4-28. [CrossRef]

40. Kahneman, D. Maps of bounded rationality: Psychology for behavioral economics. Am. Econ. Rev. 2003, 93, 1449-1475. [CrossRef]

41. Kahneman, D.; Miller, D.T. Norm theory: Comparing reality to its alternatives. Psychol. Rev. 1986, 93, 136-153. [CrossRef]

42. Bower, G.H.; Black, J.B.; Turner, T.J. Scripts in memory for text. Cogn. Psychol. 1979, 11, 177-220. [CrossRef]

43. Zhang, W.K.; Liu, Y.Y.; Fu, X.H.; Zeng, W.Z.; Ran, R.P.; Zhao, W.Y. Mental accounting, hedonic editing and agricultural water price: Evidence from farmers in Sichuan. Resour. Sci. 2014, 36, 2584-2593. (In Chinese)

44. Thaler, R.H.; Sunstein, C.R. Nudge: Improving Decisions About Health, Wealth, and Happiness; Yale University Press: New Haven, CT, USA, 2008.

(C) 2016 by the authors; licensee MDPI, Basel, Switzerland. This article is an open access article distributed under the terms and conditions of the Creative Commons Attribution (CC-BY) license (http:/ / creativecommons.org/licenses/by/4.0/). 